\title{
Adsorption of heavy metals in glacial till soil
}

\author{
ASHRAF Z. AL-HAMDAN ${ }^{1}$ and KRISHNA R. REDDY ${ }^{2, \star}$ \\ ${ }^{1}$ Department of Civil and Environmental Engineering, University of Central Florida, 162450, \\ Orlando, Florida, 32816-2450, USA \\ ${ }^{2}$ Department of Civil and Materials Engineering, University of Illinois at Chicago, 842 West \\ Taylor Street, Chicago, Illinois, 60607,USA (e-mail: kreddy@uic.edu)
}

(Received 25 March 2005; accepted 23 November 2005)

\begin{abstract}
The charged sites on soil particles are important for the retention/adsorption of metals. Metallic counterions can neutralize the intrinsic charges on the surfaces of soil particles by forming complexes. In this study, efforts have been made to determine the effect of surface potential, $\mathrm{pH}$, and ionic strength on the adsorption of four metal ions, hexavalent chromium $\mathrm{Cr}(\mathrm{VI})$, trivalent chromium $\mathrm{Cr}(\mathrm{III})$, nickel Ni(II) and cadmium $\mathrm{Cd}(\mathrm{II})$, in glacial till soil. Batch tests were performed to determine the effect of $\mathrm{pH}(2-12)$ and ionic strength $(0.001-0.1 \mathrm{M}$ $\mathrm{KCl})$ on zeta potential of the glacial till soil. The point of zero charge $\left(\mathrm{pH}_{P Z C}\right)$ of glacial till was found to be $7.0 \pm 2.5$. Surface charge experiments revealed the high buffering capacity of the glacial till. Batch adsorption experiments were conducted at natural $\mathrm{pH}(8.2)$ using various concentrations of selected metals. The adsorption data was described by the Freundlich adsorption model. Overall glacial till shows lower adsorption affinity to $\mathrm{Cr}(\mathrm{VI})$ as compared to cationic metals, $\mathrm{Cr}(\mathrm{III}), \mathrm{Ni}(\mathrm{II})$ and $\mathrm{Cd}(\mathrm{II})$.
\end{abstract}

Key words. adsorption, clays, electrokinetics, heavy metals, remediation, soil, zeta potential.

\section{Introduction}

The retention of metals by soils has been a focus of much research in recent years. The mobility and reactivity of heavy metals in soils are critically dependent on the aqueous speciation, controlling their solubility and adsorption behavior. Evaluation of remediation strategies for heavy metal-contaminated soils requires that the partitioning of contaminants between the pore water and the soil solids is understood. Modeling of the surface speciation can be used to predict the trends in adsorption behavior of heavy metals in soils with master variables such as $\mathrm{pH}$ and redox status. Application of sound thermodynamic principles to adsorption reactions provides a modeling framework that is theoretically rigorous, which can be applied for even complex adsorption reactions (Grenthe and Puigdomenech, 1997; Al-Hamdan, 2002).

The surfaces of the fine-grained soil particles are very active chemically i.e., surface sites are negatively or positively charged or they are electrically neutral. The relative proportion of metal ions attracted to these various sites depends on the degree of acidity or alkalinity of the soil, its mineralogical composition, and its content of

^ Corresponding author: (e-mail: kreddy@uic.edu) 
organic matter. The adsorption reactions that occur between metallic ions and the charged surfaces of the soil particles may involve either the formation of relatively weak complexes through cation exchange reactions or the formation of strongly bounded complexes through ligand exchange reactions. The actual nature of the association between the charged surface and the counterions depends on the mechanism of retention of the counterion with the surface i.e., the extent of adsorption depends on either the respective charges on the adsorbing surface and the metallic cation or on the intrinsic formation constants for the complexation reactions. Various models have been developed to predict and quantify the adsorption/ retention of metals by charged soil surfaces and are discussed in Schecher and McAvoy (1994) and Al-Hamdan (2002).

Adsorption/desorption process is one of the important physico-chemical processes affecting the transport of the heavy metals during electrokinetic remediation (e.g., Reddy and Chinthamreddy, 2003; Reddy et al., 2003). This importance stems from the fact that the $\mathrm{pH}$ and solution chemistry change throughout the soil during electrokinetics, affecting the adsorption/desorption process. The electrostatic adsorption models such as diffuse-layer model and triple-layer model consider simultaneously such important system properties as changes in $\mathrm{pH}$, aqueous complex formation and solution ionic strength (solution speciation). The lack of data for electrostatic adsorption model parameters for soil solid surfaces necessitates one to conduct experiments using the specific soil and heavy metals of concern to determine these parameters.

Another important aspect that complicates movement of heavy metals in soils during electrokinetic remediation process is the change in electroosmotic flow magnitude and direction. Moreover, electroosmotic flow, the movement of the pore water under electric field, depends upon zeta potential of the soil surface, which is defined as the potential existing between the shearing surface in the diffuse double layer and the pore liquid. The values of zeta potential $(\zeta)$ of soils reported to range from $+50 \mathrm{mV}$ to $-50 \mathrm{mV}$, and the zeta potential greater than zero is shown to induce electroosmotic flow towards the anode and the zeta potential less than zero is shown to induce electroosmotic flow towards the cathode during electrokinetics (Eykholt and Daniel, 1994; Yeung, 1994). The zeta potential of most charged particles is dependent on solution $\mathrm{pH}$, ionic strength, types of ionic species, temperature, and type of clay minerals (Eykholt, 1992; Shapiro and Probstein, 1993; Vane and Zang, 1997). During electrokinetics, both the $\mathrm{pH}$ and the solution speciation change throughout the soil. As a result, the zeta potential changes spatially. Consequently, the electroosmotic conductivity also changes spatially and temporally. Only recently, theoretical models for electrokinetic processes included the zeta potential as a variable. For example, the electrokinetic model developed by Shapiro and Probstien (1993) considered $\zeta$ to be a constant parameter over the entire soil sample. Eykholt and Daniel (1994) and Eykholt (1992) applied the pH-dependent zeta potential to the modified Helmoholtz-Smoluchowski's model to predict the magnitude and direction of electroosmotic flow in kaolin soil. However, these investigations neglected the 
effects of the presence of contaminants in the pore fluid on zeta potential. Jacobs et al. (1994) stated that the assumption of constant or only $\mathrm{pH}$-dependent electroosmotic flow for the purposes of electrokinetic modeling is not accurate for situations where the electroosmotic contribution to contaminant mass transport is significant and the aqueous and clay properties are variable.

The objective of this study is to investigate the $\mathrm{pH}$ changes and the solution speciation effects on the clay surface behavior. Specifically, this study evaluates the effect of $\mathrm{pH}$, ionic strength, and ionic species on the zeta potential and adsorption behavior of glacial till soil surfaces for the heavy metals $\mathrm{Cr}(\mathrm{VI}), \mathrm{Cr}(\mathrm{III}), \mathrm{Ni}(\mathrm{II})$, and $\mathrm{Cd}(\mathrm{II})$. In order to accomplish the objective, the following tasks were performed: (1) characterization of the surface charge behavior of the tested soil particles by performing potentiometric titration experiments, (2) quantification of the influence of the aqueous phase properties (i.e., pH, ionic strength and metal type and concentration) on the zeta potential of the tested soil particle by performing electrophoresis experiments, and (3) determination of the adsorption affinity of tested soil surface for $\mathrm{Cr}(\mathrm{VI}), \mathrm{Cr}(\mathrm{III}), \mathrm{Ni}(\mathrm{II})$, and $\mathrm{Cd}(\mathrm{II})$ by performing adsorption batch experiments. The results of this study can be utilized to incorporate the $\mathrm{pH}$ changes and solution speciation effects in the assessment and modeling of remediation processes, particularly the electrokinetic remediation of metal contaminated soils.

\section{Experimental methodology}

\subsection{MATERIALS}

Glacial till was used for this study as a representative field clayey soil. The composition and properties of this soil are given in Table 1. Four heavy metals were selected for this study: trivalent chromium $\mathrm{Cr}(\mathrm{III})$, hexavalent chromium $\mathrm{Cr}(\mathrm{VI})$, cadmium $\mathrm{Cd}(\mathrm{II})$, and nickel $\mathrm{Ni}(\mathrm{II})$. The source of these metals were: chromic chloride $\left(\mathrm{CrCl}_{3} \cdot 6 \mathrm{H}_{2} \mathrm{O}\right.$, certified Fisher Chemical) for $\mathrm{Cr}(\mathrm{III})$, potassium dichromate $\left(\mathrm{K}_{2} \mathrm{CrO}_{4}\right.$, ACS certified) for $\mathrm{Cr}(\mathrm{VI})$, nickel chloride $\left(\mathrm{NiCl}_{2} \cdot 6 \mathrm{H}_{2} \mathrm{O}\right.$, technical Fisher Chemical) for $\mathrm{Ni}(\mathrm{II})$, and cadmium chloride $\left(\mathrm{CdCl}_{2} \cdot 2.5 \mathrm{H}_{2} \mathrm{O}\right.$, ACS certified) for Cd(II). Nitric acid (ACS PUL certified) and sodium hydroxide (ACS certified) were used as titrants to change the $\mathrm{pH}$ conditions of the system. Also, sodium nitrate (ACS certified) was used as a background electrolyte. In addition to these chemicals, deionized water was used.

\subsection{SURFACE CHARGE EXPERIMENTS}

The $\mathrm{pH}$-dependent surface charge of glacial till soil was investigated through the use of potentiometric batch tests. The batch titration of the glacial till was made using $125 \mathrm{ml}$ bottles containing $10 \mathrm{ml}$ of soil suspension $(100 \mathrm{~g} / 1)$, and a predetermined amount of $\mathrm{NaNO}_{3}$ for various initial ionic strength settings (i.e., $2 \mathrm{ml}$ of $0.25 \mathrm{M}$ $\mathrm{NaNO}_{3}$ yields $\mathrm{I}=0.01 \mathrm{M}$ in $50 \mathrm{ml}$ sample). A total of 30 samples was prepared and the $\mathrm{pH}$ of each sample was changed by adding varying amounts of $0.1 \mathrm{M} \mathrm{HNO}_{3}$ or 
Table 1. Properties of the glacial till soil used in this study

\begin{tabular}{ll}
\hline Property & Result \\
\hline Mineralogy & Quartz: $31 \%$ \\
& Feldspar: $13 \%$ \\
& Carbonate: $35 \%$ \\
& Illite: $15 \%$ \\
& Chlorite: $4-6 \%$ \\
& Vermiculite: $0.5 \%$ \\
Particle size distribution (ASTM D422) & Smectite: trace \\
Gravel & \\
Sand & $0 \%$ \\
Silt & $20 \%$ \\
Clay & $44 \%$ \\
Atterberg limits (ASTM D2487) & $36 \%$ \\
Liquid limit & \\
Plastic limit & $21.7 \%$ \\
Plasticity index & $11.7 \%$ \\
Specific gravity (ASTM D854) & $10.0 \%$ \\
Hydraulic conductivity (ASTM D5084) & 2.71 \\
Cation exchange capacity (ASTM D9081) & $4.1 \times 10^{-8} \mathrm{~cm} / \mathrm{s}$ \\
pH (ASTM D4972) & $13-18 \mathrm{meq} / 100 \mathrm{~g}$ \\
Organic content (ASTM D2974) & 8.2 \\
USCS classification (ASTM D2487) & $2.8 \%$ \\
\hline
\end{tabular}

0.1 $\mathrm{M} \mathrm{NaOH}$ solution. The first half of batch samples contained 550, 500, 450, 400, $350,330,315,305,295,285,220,160,100,50$, and $15 \mathrm{ml}$ of $0.1 \mathrm{M} \mathrm{HNO}_{3}$, while the other half of batch samples contained $22,17,12,8,6,4,3,2.6,2.2,1.2,1,0.9,0.8$, 0.7 , and $0.6 \mathrm{ml}$ of $0.1 \mathrm{M} \mathrm{NaOH}$. One control sample was prepared without adding acid or base. The volume of acid or base added was carefully monitored by the use of an adjustable volume pipette which can deliver the desired solution in $0.002 \mathrm{ml}$ increments. Each sample was then diluted to a final volume of $50 \mathrm{ml}$ with deionized water. Finally, the samples were tightly capped and shaken overnight on a shaker at room temperature. After equilibrating, suspension $\mathrm{pH}$ of each sample was measured and the $\mathrm{pH}$ data of the entire batch was plotted against moles of acid (or base) added. Samples were tested in duplicates to ensure reproducibility.

Glacial till showed a significant resistance to $\mathrm{pH}$ changes in the suspension (Figure 1). Therefore, glacial till was characterized through determination of its buffering capacity. The presence of calcium carbonate or other compounds such as magnesium carbonate contribute carbonate ions to the buffering system. The presence of free carbonates in the soil is a major reason for its buffering capacity. Quantitatively, the buffering capacity of a soil is the amount of acid, expressed in millimeters, required or added to reach a $\mathrm{pH}$ of 4.5 . Therefore, a set of titration experiments were conducted to determine the glacial till buffering capacity using a glacial till suspension of $100 \mathrm{~g} / 1$ and $0.1 \mathrm{M}$ nitric acid as a titrant. The carbonate ions neutralize the acid in 


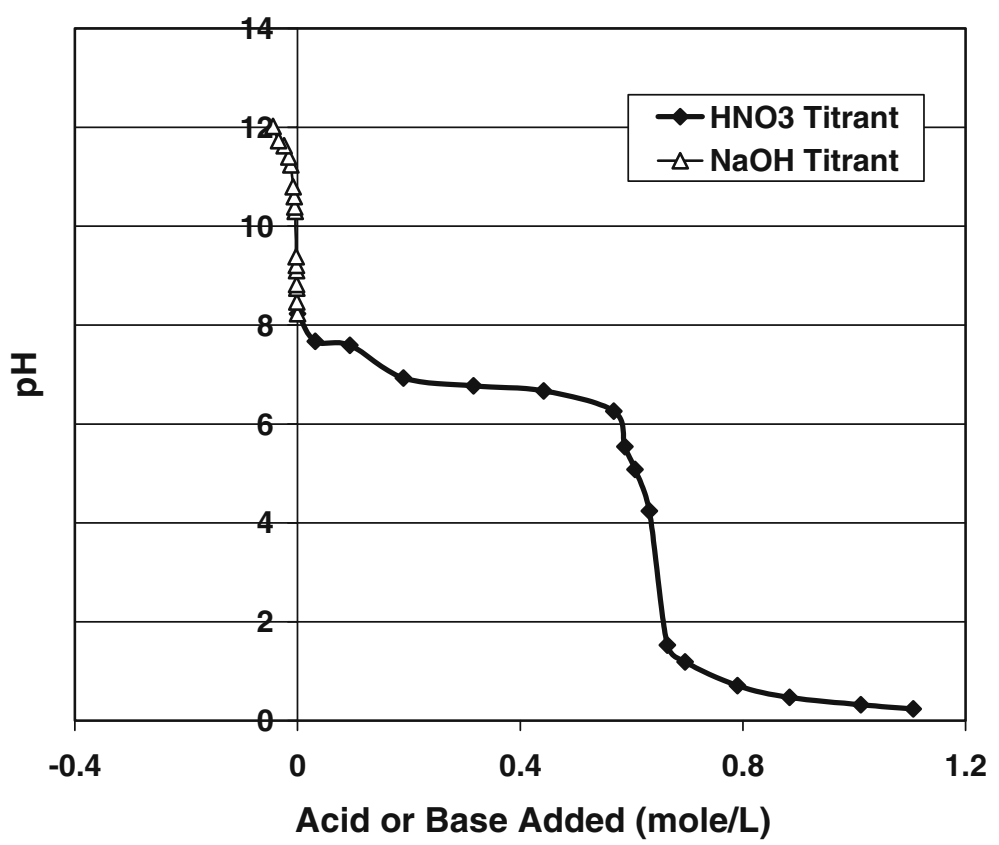

Figure 1. Acid-base titration curve of glacial till after $24 \mathrm{~h}$ contact time (suspension of $0.1 \mathrm{~g} / \mathrm{ml}$ ).

this reaction and show the buffering capacity of the sample. From the amount of acid added to the suspension, carbonate amount was calculated. This is then expressed as mg of $\mathrm{CaCO}_{3} / 1$ even though actually $\mathrm{MgCO}_{3}, \mathrm{Na}_{2} \mathrm{CO}_{3}$ or $\mathrm{K}_{2} \mathrm{CO}_{3}$ may contribute to of the alkalinity.

\subsection{ELECTROPHORESIS EXPERIMENTS}

Electrophoresis experiments were conducted to determine zeta potential of glacial till. A total of three series of experiments was conducted on glacial till. Table 2 summarizes the objective and variables of each test series. The first test series was conducted to study the effect of $\mathrm{pH}$ on zeta potential under different ionic strengths $\left(\mathrm{I}_{1}=0.001 \mathrm{M}, \mathrm{I}_{2}=0.01 \mathrm{M}\right.$ and $\left.\mathrm{I}_{3}=0.1 \mathrm{M} \mathrm{KCl}\right)$. The second series was conducted to study the effect of metal concentration of $\mathrm{Cr}(\mathrm{VI}), \mathrm{Cr}(\mathrm{III}), \mathrm{Ni}(\mathrm{II})$, and $\mathrm{Cd}(\mathrm{II})$, individually, on zeta potential. In the tests of second series, the $\mathrm{pH}$ of the suspension was 4, the ionic strength was $0.01 \mathrm{M} \mathrm{KCl}$, and the metal concentrations were $1,10,100$, and $1000 \mathrm{mg} / \mathrm{l}$. The third test series was performed to study the effect of multiple metals together in the suspension. The suspension $\mathrm{pH}$ was maintained at 4, the ionic strength was $0.01 \mathrm{M} \mathrm{KCl}$, and the concentration ratio of $\mathrm{Cr}(\mathrm{VI}): \mathrm{Ni}(\mathrm{II}): \mathrm{Cd}(\mathrm{II})$ in the suspension was 10:5:2.5. In all these tests, the suspension was $0.1 \mathrm{~g}$ of soil to $11 \mathrm{of}$ solution. The suspension $\mathrm{pH}$ was adjusted by drop wise addition of $\mathrm{HCl}$ or $\mathrm{KOH}$ solution and measured with an Orion $\mathrm{pH}$-triode probe calibrated with $\mathrm{pH}=4.00$, 7.00 , and 10.00 standards. The zeta potential of each soil suspension sample was 


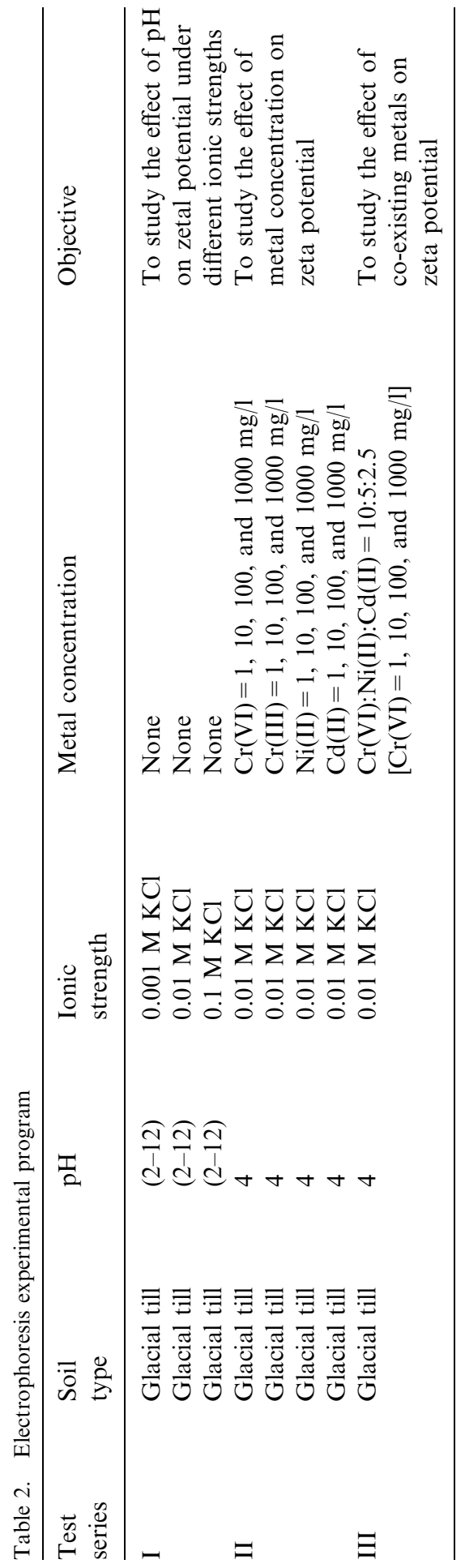


measured using zeta meter, LAZER ZEE ${ }^{\mathrm{tm}}$ Model 500. For each test series, duplicate suspensions were prepared to determine precision and repeatability of test results.

\subsection{ADSORPTION EXPERIMENTS}

The EPA batch-type test procedure was followed to determine the adsorption of heavy metals on soils (USEPA, 1992). Batch adsorption tests for glacial till soil were conducted for six different soil to solution ratios $(1: 4,1: 10,1: 40,1: 60,1: 100$, and 1:200 (mass/volume)) with a constant solution volume $(50 \mathrm{ml})$ and highest concentration of solute $\left(10^{3} \mathrm{mg} / \mathrm{l}\right)$. Nickel was used as a representative solute for finding the soil to solution ratio and the adsorption equilibrium time. The soil to solution ratio, indicating between $10 \%$ and $30 \%$ adsorption of the highest solute concentration, was selected and then used to determine the adsorption equilibrium time. The equilibrium time is the minimum amount of time required to establish a rate of change of solute concentration in solution equal to or less than $5 \%$ per 24 -h interval using the selected soil to solution ratio and the maximum initial concentration of the solute.

With the constant soil to solution ratio of $1: 10$ and known equilibrium time of $24 \mathrm{~h}$, batch adsorption tests were conducted with six different initial concentrations $(5,15,30,50,100$, and $250 \mathrm{mg} / \mathrm{l})$ for each studied metal (Cr(VI), Cr(III), Ni(II), and $\mathrm{Cd}(\mathrm{II}))$. Samples were shaken at room temperature $\left(22^{\circ} \mathrm{C}\right)$ for $24 \mathrm{~h}$ (i.e., estimated adsorption equilibrium time) then centrifuged at $3500 \mathrm{rpm}$ for $20 \mathrm{~min}$ and filtered using Wattman filter paper. The metal ion concentration in the supernatant was

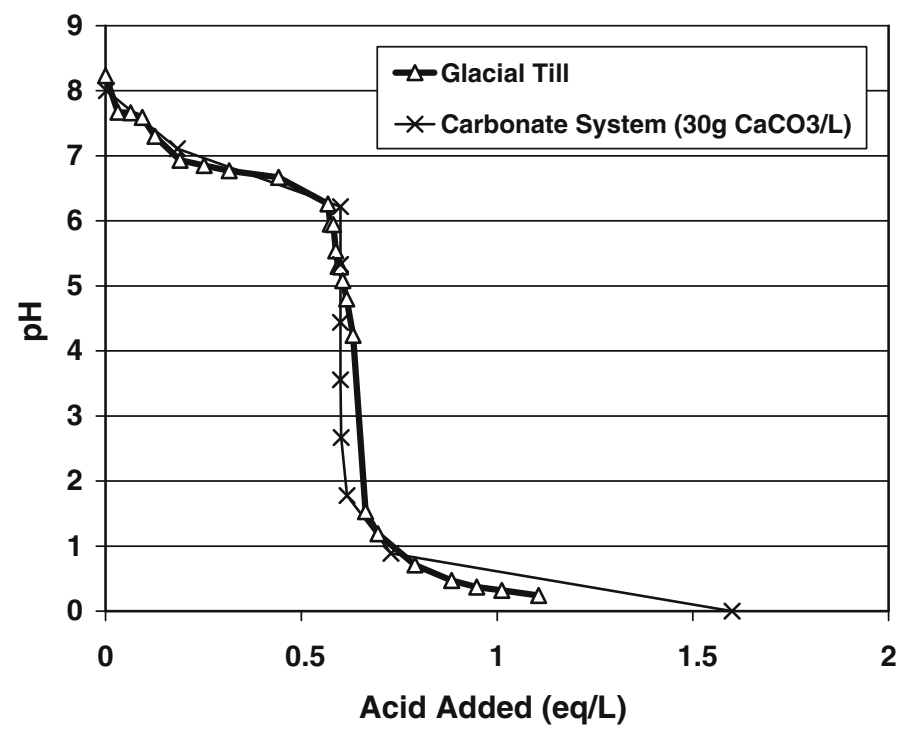

Figure 2. $\mathrm{pH}$-acid titration curves of glacial till with suspension of $0.1 \mathrm{~g} / \mathrm{ml}$ and carbonate system $(30 \mathrm{~g}$ $\left.\mathrm{CaCO}_{3} / 1\right)$. 
determined using an Atomic Absorption Spectrophotometer (AAS). The amount of metal adsorbed per unit mass of dry soil was determined by:

$$
\frac{x}{m}=\frac{C_{o}-C}{m} V
$$

where: $x / m=$ Amount of metal adsorbed per unit mass of soil, $C_{o}=$ Initial metal concentration before exposure to soil, $C=$ Metal concentration after exposure to soil at equilibrium, and $V=$ Volume of metal solution added to the reaction container.

\section{Results and Discussion}

\subsection{BUFFERING CAPACITY MEASUREMENTS}

Figure 2 shows the $\mathrm{pH}$ of the glacial till suspension versus the amount of acid added to the colloid. The titration data shows that glacial till has a high resistance to $\mathrm{pH}$ changes. Since zero volume of titrant needed to lower the $\mathrm{pH}$ of the glacial till suspension to 8.3, then the predominant form of alkalinity is $\mathrm{HCO}_{3}{ }^{-}$(Snoeyink and Jenkins, 1980). The buffering capacity of glacial till was determined about $0.6 \mathrm{eq} / 1$ as $\mathrm{HCO}_{3}$ or about $30 \mathrm{~g}$ as $\mathrm{CaCO}_{3}$ per liter of suspension (i.e., $100 \mathrm{~g}$ of soil). In other words, about $30 \%$ of the glacial till is carbonate. For comparison purpose, the chemical equilibrium model MINEQL ${ }^{+}$(Schecher and McAvoy, 1994) was used to calculate the $\mathrm{pH}$-acid titration curve of a carbonate system of $30 \mathrm{~g} \mathrm{CaCO}_{3} / 1$. Figure 2 shows that glacial till suspension of $100 \mathrm{~g} / 1$ is equivalent to a solution of $30 \mathrm{~g} \mathrm{CaCO}_{3} / 1$.

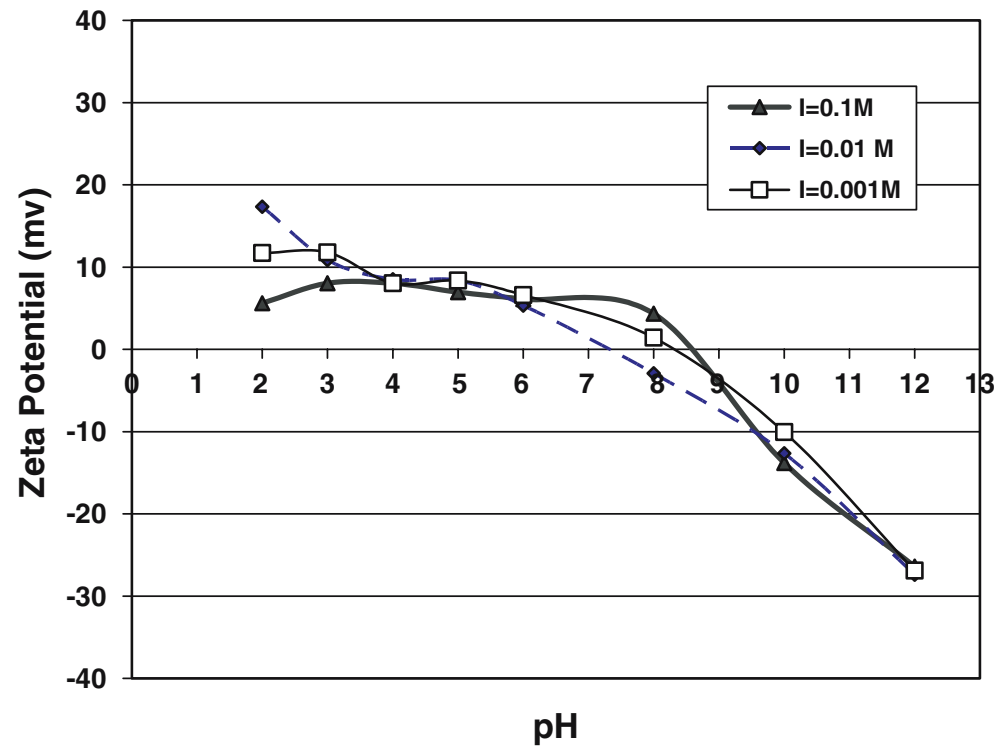

Figure 3. Effect of $\mathrm{pH}$ and electrolyte concentration on glacial till zeta potential at $0.1 \mathrm{~g} / 1$ suspension and $25{ }^{\circ} \mathrm{C}$. 


\subsection{ZETA POTENTIAL MEASUREMENTS}

The effect of $\mathrm{pH}$ on zeta potential of glacial till is shown in Figure 3. The zeta potential of glacial till was found to be a function of $\mathrm{pH}$, ranging at background electrolyte of $0.001 \mathrm{M}$ from an average value of $11.5 \mathrm{mV}$ to $-26.8 \mathrm{mV}$ at $\mathrm{pH}$ of 2 and 12 , respectively. However, the effect of $\mathrm{pH}$ on the zeta potential of glacial till surface could be negligible since the glacial till has a very high buffering capacity. The point of zero charge $\left(\mathrm{pH}_{\mathrm{PZC}}\right)$ of glacial till is found to be about $7.0 \pm 2.5$. The variations of glacial till $\mathrm{pH}_{\mathrm{PZC}}$ could be attributed to the fact that glacial till contains many minerals such as quartz, feldspar, calcite, and illite (see Table 1), hence, glacial till was more difficult to deal with during electrophoresis experiments and in that it sometimes showed a discrepancy in the direction of particle movement toward the electrodes (i.e., at the same $\mathrm{pH}$ or ionic strength conditions, some particles had positive zeta potential values and others had negative values). However, Figure 3 also shows that glacial till zeta-potential is less sensitive to the background electrolyte concentration.

As seen in Figure 4, the zeta potential of glacial till is less sensitive to the presence of cationic heavy metals $(\mathrm{Cr}(\mathrm{III}), \mathrm{Ni}(\mathrm{II})$ or $\mathrm{Cd}(\mathrm{II}))$ at $\mathrm{pH}=4.0$. However, the zeta potential of glacial till shifts towards more negative as the concentration of $\mathrm{Cr}(\mathrm{VI})$ increases. This may be attributed to the fact that the average zero point of charge of glacial till is higher than the $\mathrm{pH}$ at which experiments were performed (i.e., $\mathrm{pH}=4$ ), leading to more sensitivity of glacial till to the negatively charged ions $\left(\mathrm{CrO}_{4}{ }^{2-}\right)$ than to the positive ions $\left(\mathrm{Ni}^{2+}, \mathrm{Cd}^{2+}, \mathrm{Cr}^{3+}\right)$.

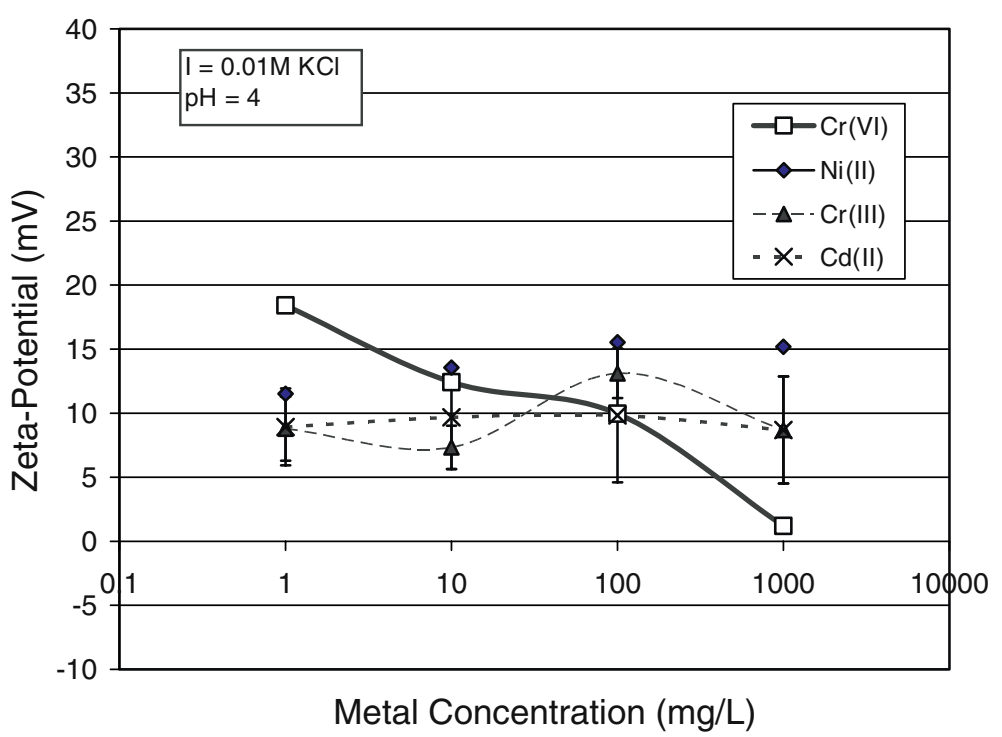

Figure 4. Effect of metal concentration on glacial till zeta potential: all samples at $\mathrm{pH}=4.0,0.01 \mathrm{M} \mathrm{KCl}$, $0.1 \mathrm{~g} / 1$ suspension, and $22{ }^{\circ} \mathrm{C}$. 

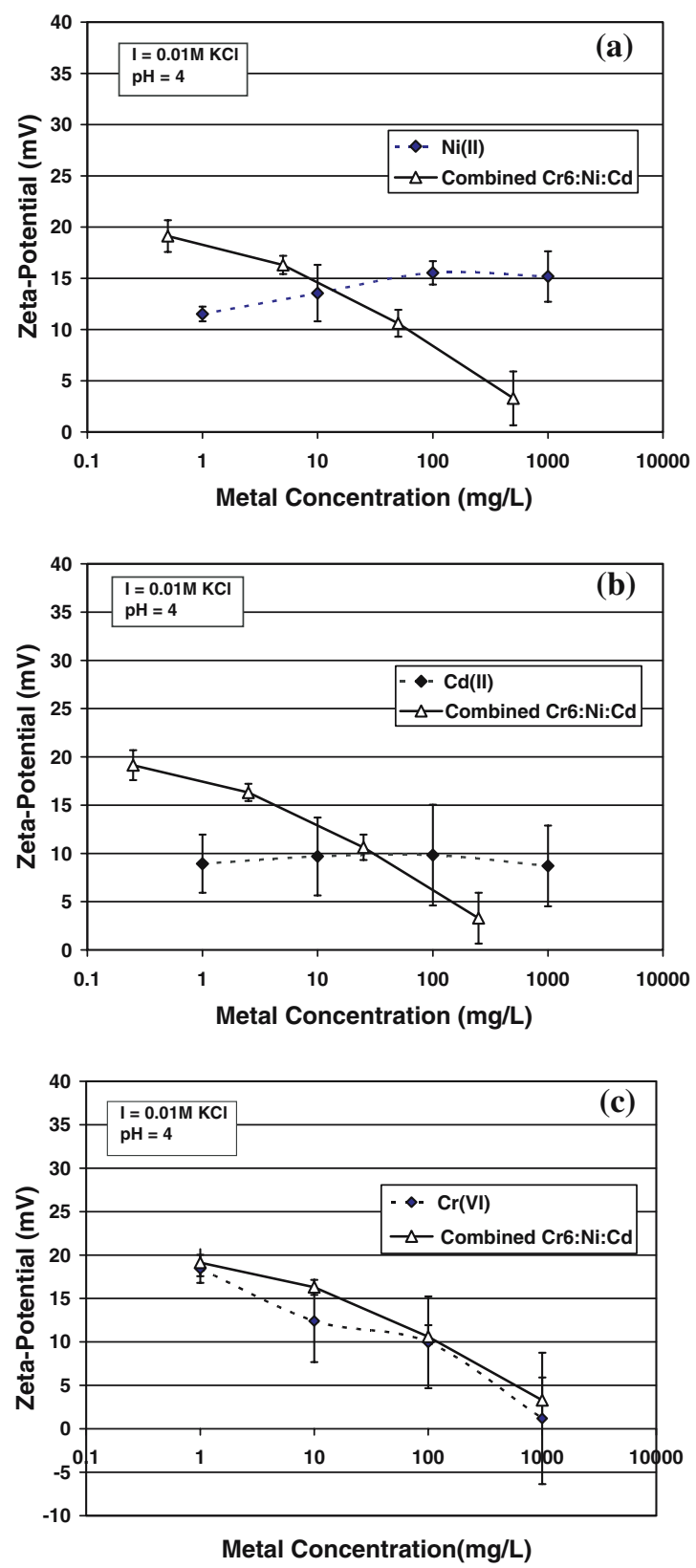

Figure 5. Effect of the presence of $\mathrm{Ni}(\mathrm{II}), \mathrm{Cd}(\mathrm{II})$, and $\mathrm{Cr}(\mathrm{VI})$ as a single or combined with other metals on glacial till zeta potential: all samples at $\mathrm{pH}=4.0,0.01 \mathrm{M} \mathrm{KCl}, 0.1 \mathrm{~g} / 1$ suspension, and $25^{\circ} \mathrm{C}$, and $\mathrm{Cr}(\mathrm{VI}): \mathrm{Ni}(\mathrm{II}): \mathrm{Cd}(\mathrm{II})$ ratio of 10:5:2.5.

Figure 5 shows the effects of coexisting of $\mathrm{Cr}(\mathrm{VI}), \mathrm{Ni}(\mathrm{II})$ and $\mathrm{Cd}(\mathrm{II})$ on the zeta potential of glacial till as compared to the situations where individual metal $(\mathrm{Cr}(\mathrm{VI})$, $\mathrm{Ni}(\mathrm{II})$ and $\mathrm{Cd}(\mathrm{II}))$ present alone. The zeta potential of combined metal system is 


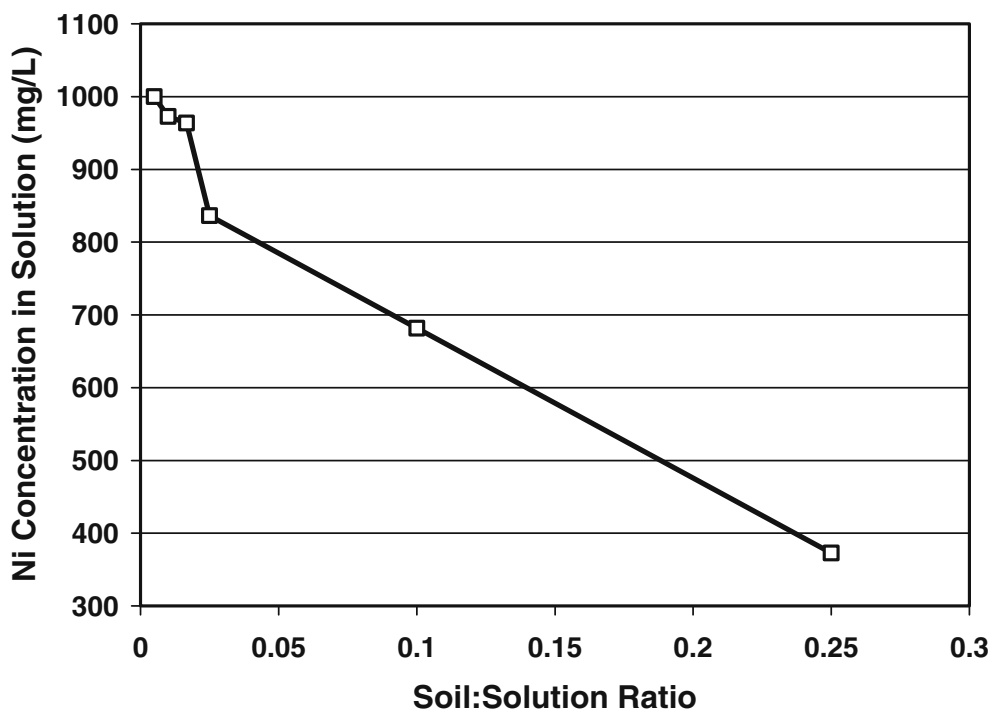

Figure 6. Distribution of nickel concentration after $24 \mathrm{~h}$ of contact time with glacial till as a function of soil to solution ratio at $22{ }^{\circ} \mathrm{C}$.

approximately the same as the zeta potential of $\mathrm{Cr}(\mathrm{VI})$ alone system, indicating that the zeta potential was not affected by the presence of $\mathrm{Ni}(\mathrm{II})$ and $\mathrm{Cd}(\mathrm{II})$. The point of zero charge of the glacial is higher than the $\mathrm{pH}=4$ of the tested systems, implying that the glacial till surfaces are positively charged and are impacted by the presence of negatively charged $\mathrm{Cr}(\mathrm{VI})$ species such as $\mathrm{CrO}_{4}{ }^{2-}$.

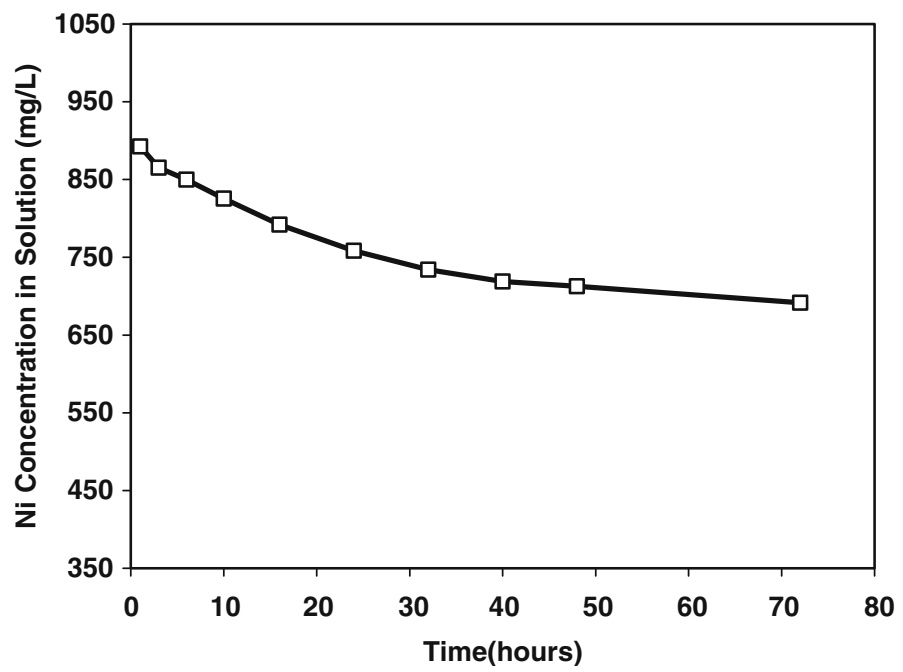

Figure 7. Distribution of nickel concentrations in glacial till as a function of contact time at $22{ }^{\circ} \mathrm{C}$ and 1:10 soil to solution ratio. 

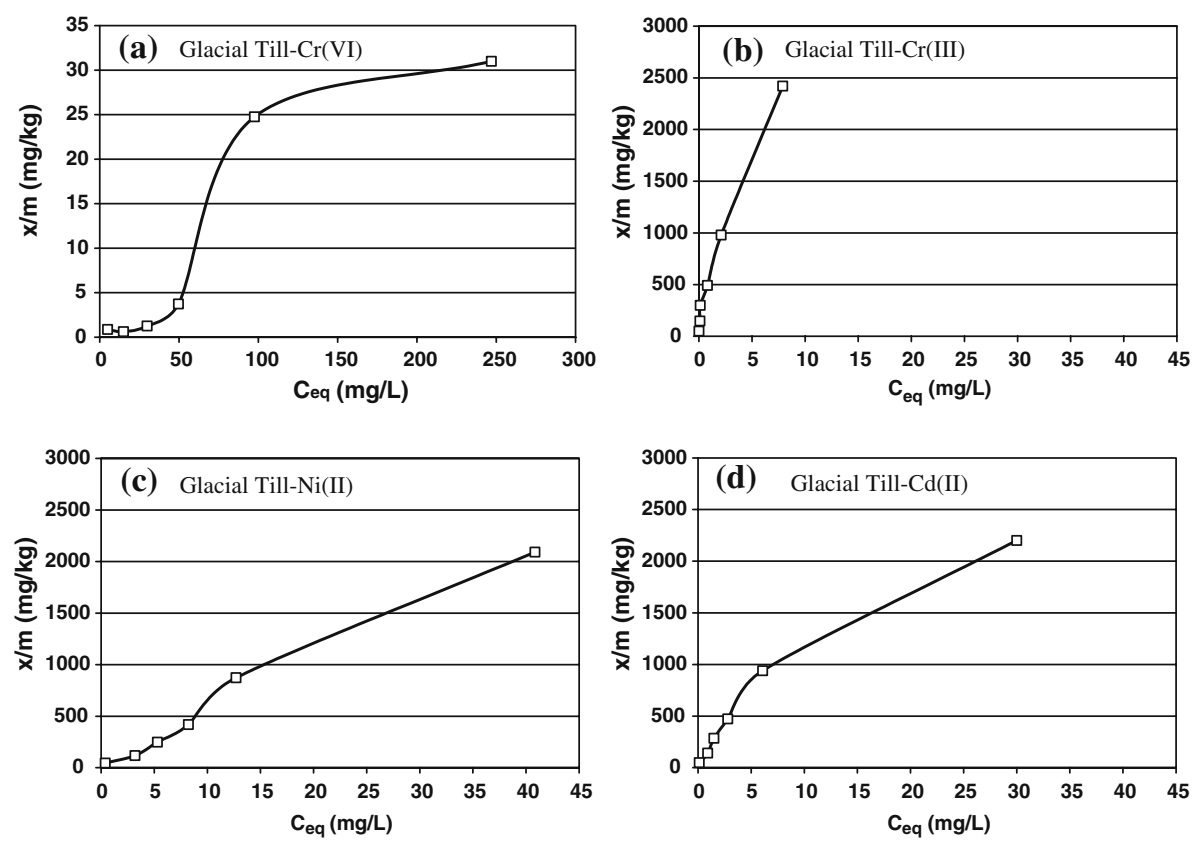

Figure 8. Adsorption isotherms of hexavalent chromium, trivalent chromium, nickel, and cadmium by glacial till at natural $\mathrm{pH}$ condition $(\mathrm{pH}=8.2), 22{ }^{\circ} \mathrm{C}$, and ionic strength of $0.1 \mathrm{M}$.

\subsection{ADSORPTION MEASUREMENTS}

As shown in Figure 6, as the soil to solution ratio of glacial till soil increases, the concentration of the nickel in the solution decreases, indicating that the amount of the nickel adsorbed to the soil increases. Figure 6 shows that at the soil to solution ratio of $1: 10$, about $16 \%$ of nickel is adsorbed by glacial till. Therefore, the soil to solution ratio used for the adsorption batch tests in this study was 1:10 (USEPA, 1992).

Figure 7 shows that as the equilibrium time increases, the concentration of the nickel in the solution decreases, indicating that the amount of the nickel adsorbed to the soil increases. However, the change in the nickel concentration in the solution with time decreases as the equilibrium time increases. The minimum amount of time at which the rate of change of nickel concentration in the solution equal to or less than $5 \%$ per 24 -interval was $24 \mathrm{~h}$ for glacial till. Therefore, the selected equilibrium time for the adsorption batch tests for glacial till was $24 \mathrm{~h}$.

Figure 8 shows the adsorption isotherms of the $\mathrm{Cr}(\mathrm{VI}), \mathrm{Cr}(\mathrm{III}), \mathrm{Ni}(\mathrm{II})$, and $\mathrm{Cd}(\mathrm{II})$ by glacial till at natural $\mathrm{pH}$ conditions (i.e., $\mathrm{pH}=8.2$ ). In general, the adsorption of cationic $\mathrm{Cr}(\mathrm{III}), \mathrm{Ni}(\mathrm{II})$ and $\mathrm{Cd}(\mathrm{II})$ increases with the increase in their concentration in solution. This adsorption behavior is attributed to precipitation of these heavy metals due to high $\mathrm{pH}$ and high acid buffering capacity of 
glacial till. The adsorption behavior of $\mathrm{Cr}(\mathrm{VI})$ is significantly different than that of cationic heavy metals (Cr(III), Ni(II) and $\mathrm{Cd}(\mathrm{II})$ ). Adsorption of $\mathrm{Cr}(\mathrm{VI})$ increases with the increase in $\mathrm{Cr}(\mathrm{VI})$ concentration in solution, but after reaching its adsorption capacity, most of the $\mathrm{Cr}(\mathrm{VI})$ exists in solution. $\mathrm{Cr}(\mathrm{VI})$ exists as anionic complexes such as $\mathrm{CrO}_{4}{ }^{2-}$ and adsorbs to the positively charged surfaces of glacial till. Once, these positively charged sites are exhausted, the adsorption of $\mathrm{Cr}(\mathrm{VI})$ ceases, leading to increases in solution concentrations. The measured $\mathrm{Cr}(\mathrm{VI})$ adsorption is consistent with the measured lower surface charge of glacial till (zeta potential).

\subsection{ADSORPTION MODELING}

The selection of adsorption model depends on the system behavior. If the system does not display a $\mathrm{pH}$ dependent behavior, then the adsorption model depends on the shape of the resulting adsorption curves. Because of the glacial till's high buffering capacity, adsorption in glacial till was assumed to be a $\mathrm{pH}$-independent process, and a regression analysis was performed to evaluate the appropriate adsorption model (Al-Hamdan, 2002). Based on this evaluation, the Freundlich model was found to best represent the adsorption isotherms for all tested metals. The mass action equation representing the Freundlich model is written as:

$$
\begin{aligned}
& S O H+(1 / n) M \leftrightarrow S O H \bullet M \\
& K_{F}=\frac{[S O H \bullet M]}{[M]^{1 / n}[S O H]}
\end{aligned}
$$

The adsorption model parameters $n$ and $K_{F}$ of glacial till for $\mathrm{Cr}(\mathrm{VI}), \mathrm{Cr}(\mathrm{III}), \mathrm{Ni}(\mathrm{II})$, and $\mathrm{Cd}(\mathrm{II})$ are calculated and are summarized in Table 3.

\section{Conclusions}

Based on the results of the potentiometric, electrophoresis, and adsorption batch experiments of glacial till using heavy metals, $\mathrm{Cr}(\mathrm{VI}), \mathrm{Cr}(\mathrm{III}), \mathrm{Ni}(\mathrm{II})$ and $\mathrm{Cd}(\mathrm{II})$, the following conclusions can be drawn:

Table 3. Freundlich adsorption model parameters

\begin{tabular}{llc}
\hline Metal & $n$ & $\log K_{F}$ \\
\hline Cadmium, Cd(II) & $0.68 \pm 0.1$ & $-0.14 \pm 0.1$ \\
Nickel, Ni(II) & $0.89 \pm 0.1$ & $0.36 \pm 0.2$ \\
Trivalent Chromium, Cr(III) & $0.72 \pm 0.2$ & $0.69 \pm 0.1$ \\
Hexavalent Chromium, Cr(VI) & $1.27 \pm 0.1$ & $-1.15 \pm 0.05$ \\
\hline
\end{tabular}


1. The aqueous properties, specifically $\mathrm{pH}$, ionic strength and the presence of the heavy metals $\mathrm{Cr}(\mathrm{III}), \mathrm{Ni}(\mathrm{II})$, and $\mathrm{Cd}(\mathrm{II})$ single or combined in the system, do not significantly affect the zeta potential of a glacial till surface. However, Cr(VI) slightly affected the surface potential of glacial till. The zeta potential value for glacial till shifts to a more negative value if $\mathrm{pH}$ increases, however, the $\mathrm{pH}_{\mathrm{PZC}}$ of glacial till is high (i.e., about $7.0 \pm 2.5$ ).

2. The glacial till possesses a very high buffering capacity (i.e., $30 \%$ as $\mathrm{CaCO}_{3}$ ), and its $\mathrm{pH}$ is hardly changed by adding acid to it; hence the adsorption behavior could be assumed to be $\mathrm{pH}$-independent. However, at $\mathrm{pH}=8.2$, glacial till possesses a lower adsorption affinity to $\mathrm{Cr}(\mathrm{VI})$ as compared to cationic metals, $\mathrm{Cr}$ (III), $\mathrm{Ni}$ (II) and $\mathrm{Cd}(\mathrm{II})$.

3. The ion-surface complexation isotherm is represented by the Freundlich model. The models parameters of $\mathrm{Ni}(\mathrm{II}), \mathrm{Cd}(\mathrm{II}), \mathrm{Cr}(\mathrm{III})$, and $\mathrm{Cr}(\mathrm{VI})$ are: $p \mathrm{~K}_{\mathrm{Ni}(\mathrm{II})}$ $=-0.36 \pm 0.2, n_{\mathrm{Ni}(\mathrm{II})}=0.89 \pm 0.1, p \mathrm{~K}_{\mathrm{Cd}(\mathrm{II})}=0.14 \pm 0.1, n_{\mathrm{Cd}(\mathrm{II})}=0.68 \pm 0.1, p \mathrm{~K}_{\mathrm{Cr}(\mathrm{III})}$ $=-0.69 \pm 0.1, n_{\mathrm{Cr}(\mathrm{III})}=0.72 \pm 0.2, p \mathrm{~K}_{\mathrm{Cr}(\mathrm{VI})}=1.15 \pm 0.05$, and $n_{\mathrm{Cr}(\mathrm{VI})}=1.27 \pm 0.1$.

Overall this study showed that glacial till possesses a high acid buffering capacity and shows lower adsorption affinity to $\mathrm{Cr}(\mathrm{VI})$ as compared to cationic metals, $\mathrm{Cr}(\mathrm{III}), \mathrm{Ni}(\mathrm{II})$ and $\mathrm{Cd}(\mathrm{II})$.

\section{References}

Al-Hamdan, A.Z. (2002) Speciation, distribution and mobility of heavy metals in soils during electrokinetic remediation, Ph.D. Thesis, University of Illinois at Chicago, Illinois, USA.

Eykholt, G.R. (1992) Driving and complicating features of elecktrokinetic treatment of soils, Ph.D. Thesis, University of Texas at Austin, Texas, USA.

Eykholt, G.R. and Daniel, D.E. (1994) Impact of system chemistry on electroosmosis in contaminated soil, Journal of Geotechnical Engineering, 120, 797-815.

Grenthe, I. and Puigdomenech, I. (1997) Modeling in Aquatic Chemistry, Royal Institute of Technology, Stockholm, Sweden.

Jacobs, R.A., Sengun, M.Z., Hicks, R.E. and Probstein, R.F. (1994) Model and experiments on soil remediation by electric fields, Journal of Environmental Science and Health, A29(9), 1933-1955.

Reddy, K.R. and Chinthamreddy, S. (2003) Sequentially enhanced electrokinetic remediation of heavy metals in low buffering clayey soils, Journal of Geotechnical and Geoenvironmental Engineering, 129(3), 263-277.

Reddy, K.R., Chaparro, C. and Saichek, R.E. (2003) Iodide-enhanced electrokinetic remediation of mercury-contaminated soils, Journal of Environmental Engineering, 129(12), 1137-1148.

Schecher, W. D. and McAvovy, W. D. (1994) MINEQL + : A chemical equilibrium program for personal computer, User's Manual, version 3.0, Environmental Research Software, Hallowell, Maine.

Shapiro, A.P. and Probstein, R.F. (1993) Removal of contaminants from saturated clay by electroosmosis, Environmental Science and Technology, 27, 283-291.

Snoeyink, V.L. and Jenkins, D. (1980) Water Chemistry, John Wiley and Sons, New York.

USEPA (1992) Batch-type procedures for estimating soil adsorption of chemicals. EPA/530/ SW-87/006-F. 
Vane, L.M. and Zang, G.M. (1997) Effect of aqueous phase properties on clay particle zeta potential and electroosmotic permeability: Implications for electrokinetic soil remediation processes, Journal of Hazardous Materials, 55, 1-22.

Yeung, A.T. (1994) Electrokinetic flow processes in porous media and their applications, In: Corapcioglu, M.Y. (ed.). Advances in Porous Media, Elsevier, The Netherlands, pp. 309395. 